\title{
Prevalence of Human Intestinal Parasites in Tabriz City of Iran During 2018 and the Importance of These Parasites in Public Health
}

\author{
Yagoob Garedaghi ${ }^{* \circledast}$, Hamidreza Hassanzadeh Khanmiri ${ }^{\circledR}$ \\ 'Department of Parasitology, Tabriz Branch, Islamic Azad University, Tabriz, Iran \\ ${ }^{2}$ Department of Basic Sciences, Maragheh Branch, Islamic Azad University, Maragheh, Iran
}

\begin{abstract}
Introduction: Intestinal parasitic infections are among the main problems in developing countries. It is estimated that over 4.5 billion people in the world have been infected with a variety of intestinal parasites. Numerous studies conducted in different parts of Iran showed the spread of intestinal parasite infections in different urban and rural areas. However, the prevalence of these infections significantly reduced in recent years due to improvements in public health.

Methods: In this cross-sectional study conducted in a hospital in Tabriz city of Iran, 700 stool samples were collected during one year and studied using formalin-ether concentration method and Lugol's iodine staining.

Results: In this study, six types of parasites including Giardia lamblia, Entamoeba histolytica, Entamoeba coli, Chilomastix mesnili, Blastocystis hominis, and Enterobius vermicularis were detected in 700 fecal samples. A total of $112(16 \%)$ samples were infected, among which $43(40 \%)$ were infected with Giardia lamblia, 35 (32\%) with Entamoeba histolytica, 20 (18\%) with Enterobius vermicularis, 10 (9\%) with Entamoeba coli, $3(0.026 \%)$ with Blastocystis hominis, and $1(0.008 \%)$ with Chilomastix mesnili.

Conclusion: In this study, the highest prevalence of infection belonged to Giardia lamblia (40\%), which is consistent with the statistics published by the World Health Organization. According to the findings of this study, it can be concluded that despite the increase in the provision of health services in cities and villages, the prevalence of intestinal parasites, especially Giardia lamblia, is one of the major problems in the region. Therefore, there is a need for proper and coherent health planning in the region and accurate and up-to-date epidemiological information.

Keywords: Prevalence, Human, Intestinal parasites, Public health, Tabriz
\end{abstract}

Received: November 3, 2020, Accepted: December 17, 2020 , ePublished: December 30, 2020

\section{Introduction}

The prevalence of intestinal parasitic diseases is directly related to the level of health and socio-economic status in each region. The prevalence of these diseases is not the same in different parts of the country and varies depending on weather conditions, public health, and eating habits $(1,2)$. Factors such as gender, age, and level of education can play decisive roles in some parasitic infections such as Enterobius vermicularis infections and its low prevalence in other age groups can be justified according to the pattern of parasite transmission $(3,4)$. Parasitic infections are major causes of morbidity and mortality in children. Numerous studies performed on different people in the world have reported that the percentage of infection with gastrointestinal parasites is $91 \%$. Parasites such as Giardia lamblia and Entamoeba histolytica are often transmitted through water and directly from person to person. The first case of food borne giardiasis was reported in the USA state of Soda, which originated from home-made salmon. Amoebiasis is a human parasitic infection caused by a protozoan called Entamoeba histolytica with varying degrees of clinical symptoms. This amoeba lives mainly in the large intestine and feeds on starch and bacteria (5). Approximately 500 million people are infected with Entamoeba histolytica and about $10 \%$ of them have clinical symptoms. According to the World Health Organization, 48 million people are diagnosed with severe forms of the disease each year, of whom 7000 die from the infection. Amoebiasis is still one of the most important problems in tropical and subtropical regions, especially areas with poor health and socio-economic status (6). Geographical location, climate, and social and cultural characteristics of Iran have provided a suitable condition for the activity of various parasites; therefore, controlling and preventing intestinal parasites are of great importance due to their high prevalence. The physical, psychological, and social consequences of them are of great importance in society. Despite some risk factors in these areas and exposure of people to the parasite, our knowledge of the underlying causes of these protozoan infections is still limited (7). 
In fact, special geographical-cultural conditions, health status, and nutrition of people have caused the spread of this type of protozoan infection in these areas, including the city of Tabriz, especially in the hot season.

Given the large population living in the city of Tabriz, the fight against infections and treatment of parasitic infectious diseases seem necessary. Therefore, there is a need for proper and coherent health planning in the region and accurate and up-to-date epidemiological information (8).

The aim of this study was to investigate the prevalence of intestinal protozoans including Entamoeba histolytica and Giardia lamblia and their distribution by gender in Tabriz region.

\section{Materials and Methods}

In this cross-sectional descriptive study performed in one of the hospitals of Tabriz, 700 fecal samples were collected from the patients. Microscopic examination was performed after using formalin-ether concentration method and Lugol's iodine staining, and in cases where there were diarrhea specimens, direct smear with physiological serum was performed to detect protozoan trophozoites. Information forms were completed for each of the tested participants.

First, stool containers with the individual number affixed to them were distributed to the study population, and the samples were collected and sent to the laboratory. In the direct smear method, a small amount of stool sample was mixed with a drop of physiological serum on a slide and after placing a slide on it, it was examined microscopically. In the formalin-ether concentration method, some of the feces was dissolved in $10 \mathrm{~mL}$ of $10 \%$ formalin and vigorously mixed with $7 \mathrm{~mL}$ of the filtered suspension. Afterwards, ether was added to it and centrifuged at $2000 \mathrm{rpm}$ for 2 minutes. Then, Lugol's iodine was added to the bottom sediment and examined under a microscope.

The results were analyzed using SPSS software.

\section{Results}

Six types of parasites were detected in 700 fecal samples which include Entamoeba histolytica, Giardia lamblia, Entamoeba coli, Chilomastix mesnili, Blastocystis hominis and Enterobius vermicularis. The total number of infected samples was $112(16 \%)$, of which 43 (40\%) were infected with Giardia lamblia, with the highest prevalence of infection, and $1(0.008 \%)$ was infected with Chilomastix mesnili (Tables 1 and 2).

A total of 112 samples were found to be infected, of which 72 (64\%) belonged to males. Among them, 27 were infected with Giardia lamblia (37.5\%), indicating the highest infection rate, and $1(0.01 \%)$ was infected with Chilomastix mesnili, indicating the lowest infection rate (Tables 1 and 2).

Among the female population (40), 36\% were diagnosed with the parasite, of whom $16(40 \%)$ were infected with Giardia lamblia and no one was infected with Chilomastix mesnili (Tables 1 and 2).

\section{Discussion}

Intestinal parasitic infections are among the main problems in developing countries. By increasing health standards and controlling vectors or intermediate hosts, most industrialized countries have successfully reduced their prevalence rate (9). In developing countries, socioeconomic and geographical factors such as natural disasters are considered as problems. In fact, these countries are located in tropical regions with humid climate and all are characterized by poverty, malnutrition, high population density, lack of access to safe water, and poor health services, which provide optimal conditions for the growth and transmission of intestinal parasites (10). Inadequate studies on infection and parasitism, lack of attention to developing countries and their problems, and lack of timely treatment can increase the rate of parasitic infections. The prevalence of Giardia lamblia is one of the most important problems in developing countries such as Iran. Geographical conditions, poor

Table 1. Frequency and Percentage of Parasitic Infections in Tabriz City

\begin{tabular}{lcc}
\hline Type of Parasite & Number of Infected People & Percent \\
\hline Entamoeba histolytica & 33 & 32 \\
Giardia lamblia & 43 & 40 \\
Entamoeba coli & 10 & 9 \\
Chilomastix mesnili & 1 & 0.008 \\
Blastocystis hominis & 3 & 0.026 \\
Enterobius vermicularis & 20 & 18 \\
Total & 112 & 100 \\
\hline
\end{tabular}

Table 2. Frequency and Percentage of Parasitic Infection in Tabriz City by Gender

\begin{tabular}{|c|c|c|c|c|c|c|c|c|c|c|c|c|c|}
\hline \multirow{3}{*}{ Gender } & \multicolumn{12}{|c|}{ Type of parasite } & \multirow{3}{*}{$\begin{array}{c}\text { Total } \\
\text { No. }\end{array}$} \\
\hline & \multicolumn{2}{|c|}{$\begin{array}{c}\text { Entamoeba } \\
\text { histolytica }\end{array}$} & \multicolumn{2}{|c|}{ Giardia lamblia } & \multicolumn{2}{|c|}{$\begin{array}{c}\text { Chilomastix } \\
\text { mesnili }\end{array}$} & \multicolumn{2}{|c|}{$\begin{array}{c}\text { Blastocystis } \\
\text { hominis }\end{array}$} & \multicolumn{2}{|c|}{ Entamoeba coli } & \multicolumn{2}{|c|}{$\begin{array}{c}\text { Enterobius } \\
\text { vermicularis }\end{array}$} & \\
\hline & No. & $\%$ & No. & $\%$ & No. & $\%$ & No. & $\%$ & No. & $\%$ & No. & $\%$ & \\
\hline Male & 22 & 30.5 & 27 & 37.5 & 1 & 0.01 & 2 & 2.7 & 7 & 9.7 & 13 & 18 & 72 \\
\hline Female & 13 & 32.5 & 16 & 40 & 0 & 0 & 1 & 2.5 & 3 & 7.5 & 7 & 17.5 & 40 \\
\hline
\end{tabular}


nutrition, socio-economic status of Iran can provide a suitable condition for the spread of parasitic infections. However, the prevalence of parasitic infections varies in different parts of the country. Studies have shown that the prevalence of intestinal parasitic infections is higher in younger people, especially children (11).

Studies have shown that the prevalence of pathogenic intestinal parasites decreased from $31 \%$ to $10 \%$ during 2006 due to improvements in health care services in different classes of society, increasing income, high level of maternal education, availability of safe water, and access to health services (12).

According to the results, the prevalence of protozoan infection is higher than worm infection. This could be due to the fact that these protozoans reproduce more easily than intestinal worms, which increases their release into the environment. Moreover, these protozoans can be transmitted directly and indirectly, which helps to increase their prevalence. Therefore, their prevalence has a direct relationship with the level of public health care services (13). The statistics of the last few years also confirm the findings of this study.

Considering the ecological and climatic conditions of East Azerbaijan province and the existence of suitable conditions for the spread and transmission of parasites, especially intestinal parasites, the study of parasitic diseases caused by protozoans and worms in Tabriz with a large population is of great importance. From a medical and health point of view, it is important that prevention and control programs should be implemented.

In this study, the percentage of infection is higher in males than in females. However, some studies have reported no differences between males and females in the incidence of intestinal parasites. It seems that the occupational, health, and social conditions of individuals affect it.

In some other studies, the higher prevalence of parasitic infections, especially Giardia lamblia, in males has been confirmed.

Among worm infestations, Enterobius vermicularis infection was the most common, which is probably due to the ease of transmission of the parasite. In a study conducted in Turkey, the prevalence of intestinal parasites in three areas of Sivas region was $37.2 \%$ and 11 species of parasites were isolated, among which Giardia lamblia and Enterobius vermicularis had the highest percentage and the highest rate of infection was observed among the children aged 7-15 years (14). Enterobius vermicularis infection (15\%) had the highest prevalence among students in Thailand, and $46 \%$ of boys and $38.8 \%$ of girls reported it (15).

In the present study, the rate of infection was reported to be higher in men than in women, and studies conducted on children in kindergartens and primary schools in Babol showed that the rate of infection is significantly higher in boys than girls (16).

Giardia lamblia infection is widespread worldwide and it is the most common parasitic infection which is known to be a major cause of diarrhea outbreaks due to contamination of water sources. This type of infection is affected by the same socioeconomic conditions which also affect the spread of Entamoeba histolytica.

In this study, the highest prevalence belonged to Giardia lamblia infection (40\%), which is consistent with the statistics published by the World Health Organization (17).

According to studies conducted in other parts of the country, Giardia lamblia is one of the most commonly found parasites. In a study conducted in Tehran, Giardia lamblia was the most commonly found parasite (8.0\%) followed by Entamoeba coli (5.5\%), Blastocystis hominis (3.3\%), Endolimax nana (2.8\%), and Entamoeba histolytica $(1.7 \%)(18,20)$.

Numerous studies have been performed in Iran regarding the prevalence of intestinal parasites. Kousha et al reported a prevalence of $8.8 \%$ for Giardia lamblia (19). The reason for the greater prevalence of this parasite can be attributed to the resistance of Giardia lamblia cysts and their survival outside the human body for months and the transmission of infection through water.

In a systematic review study conducted in Iran in 2013, the prevalence of Giardia lamblia in the whole country was estimated to be $14.7 \%$ (20).

One of the indicators for measuring the health status of the community is the determination of the prevalence of parasitic infections. One of the essential things for the health of any society is to know the epidemiology and the relationship between such infections and environmental and social factors. Obtaining this information provides an accurate understanding of the extent of environmental pollution as well as the state of individual and family health (21).

According to the various questions that were asked of the infected people, most of them were infected due to lack of personal hygiene, use of non-drinkable water in the city, consumption of contaminated food, and inadequate washing of vegetables. Avoiding the use of human fertilizer in fields to control disease vectors such as flies and beetles and disinfecting water should be considered in the prevention of infection. Attention to environmental health, the health of cooks and treatment of healthy carriers, personal hygiene, and health education are the basic pillars of disease prevention and control (22).

According to the findings of this study, it can be concluded that despite the increase in the provision of health services in cities and villages, the prevalence of intestinal parasites, especially Giardia lamblia, is one of the major problems in the region. Therefore, there is a need for proper and coherent health planning in the region and up-to-date and accurate epidemiological information. 


\section{Conflict of Interests}

The authors declare that they have no conflict of interests.

\section{Ethical Issues}

In this research, ethical considerations have been fully observed.

\section{Acknowledgements}

The authors would like to express their deep gratitude to Islamic Azad University Tabriz Branch for offering valuable theoretical and practical contributions to the research team in the present study.

\section{Authors' Contribution}

YG did writing and editing of the manuscript. HHKH designed the study and did data collection and statistical analysis.

\section{Funding}

The authors received no financial support for the research, authorship, and publication of this article.

\section{References}

1. Anantaphruti MT, Waikagul J, Maipanich W, Nuamtanong S, Pubampen S. Soil-transmitted helminthiases and health behaviors among schoolchildren and community members in a westcentral border area of Thailand. Southeast Asian J Trop Med Public Health. 2004;35(2):260-266.

2. Andiran N, Acikgoz ZC, Turkay S, Andiran F. Blastocystis hominis--an emerging and imitating cause of acute abdomen in children. J Pediatr Surg. 2006;41(8):1489-1491. doi:10.1016/j. jpedsurg.2006.04.037

3. Anvari-Tafti $\mathrm{MH}$, Mirjalili MM, Aghabagheri M. Prevalence of intestinal parasites in children attending day-care centers in Yazd city, Iran. J Community Health Res. 2014;3(2):96-102.

4. Mohseni-Moghadam F, Jafarpoor P, Shahidi Zandi B, Khodadadi A, Shabani Z. Prevalence of giardiasis in daycare children at Rafsanjan nurseries in 2003. J Rafsanjan Univ Med Sci. 2007;6(3):193-200. [Persian].

5. Molazade P, Rahimi MR. Prevalence of Intestinal Parasitic Infections Among Earthquake Children in Bam City. In: 8th Environmental Health Congressin Iran, Tehran University of Medical Sciences; 2005:118.

6. Momen Heravi M, Rasti S, Vakili Z, Moraveji A, Hosseini F. Prevalence of intestinal parasites infections among Afghan children of primary and junior high schools residing Kashan city, Iran, 2009-2010. Iran J Med Microbiol. 2013;7(1):46-52. [Persian].

7. Ragunathan L, Kalivaradhan SK, Ramadass S, Nagaraj M, Ramesh K. Helminthic infections in school children in Puducherry, South India. J Microbiol Immunol Infect. 2010;43(3):228-232. doi:10.1016/

\section{s1684-1182(10)60036-9}

8. Rokni MB. The present status of human helminthic diseases in Iran. Ann Trop Med Parasitol. 2008;102(4):283-295. doi:10.1179/136485908x300805

9. Stephenson LS, Latham MC, Ottesen EA. Malnutrition and parasitic helminth infections. Parasitology. 2000;121 Suppl:S23-38. doi:10.1017/s0031182000006491

10. Tohidi F, Qorbani M. The effect of individual health education on prevention school students from intestinal parasitic infection in Gorgan. J Knowl Health. 2009;4(2):14-7. [Persian].

11. Walana W, Tay SC, Tetteh P, Ziem JB. Prevalence of intestinal protozoan infestation among primary school children in urban and peri-urban communities in Kumasi, Ghana. Sci J Public Health. 2014;2(2):52-57. doi:10.11648/j.sjph.20140202.12

12. Workneh T, Esmael A, Ayichiluhm M. Prevalence of intestinal parasitic infections and associated factors among Debre Elias primary schools children, East Gojjam Zone, Amhara Region, North West Ethiopia. J Bacteriol Parasitol. 2014;5(1):181. doi:10.4172/2155-9597.1000181

13. Wu CG, Luo XJ, Xie J, Jiang SG, Li SS, Xiao BZ. [Prevalence of Enterobius vermicularis infection of children and its influencing factors in Chongqing city]. Zhongguo Xue Xi Chong Bing Fang Zhi Za Zhi. 2012;24(6):703-706.

14. Celiksöz A, Güler N, Güler G, Oztop AY, Degerli S. Prevalence of intestinal parasites in three socioeconomically-different regions of Sivas, Turkey. J Health Popul Nutr. 2005;23(2):184-191.

15. Saksirisampant W, Prownebon J, Kanmarnee P, Thaisom S, Yenthakam S, Nuchprayoon S. Prevalence of parasitism among students of the Karen hill-tribe in Mae Chame district, Chiang Mai province, Thailand. J Med Assoc Thai. 2004;87 Suppl 2:S278-283.

16. Hedayati A, Sadraei J, Ghofranipour F. Relationship between the rate of giardiasis and knowledge and practice of prevention in primary school children in south of Tehran. Parasitol Res. 2008;104(1):169-171. doi:10.1007/s00436-008-1176-0

17. World Health Organization. Prevalence and Control of Intestinal Parasites. WHO; 1987:749.

18. Sharif M, Daryani A, Asgarian F, Nasrolahei M. Intestinal parasitic infections among intellectual disability children in rehabilitation centers of northern Iran. Res Dev Disabil. 2010;31(4):924-928. doi:10.1016/j.ridd.2010.03.001

19. Kousha A, Hakimi S, Fallah E, Nokhahi I, Sarafraz S, Shahnami A. Prevalence of intestinal parasites among symptomless primary school children attending urban health centers, Tabriz. Med J Tabriz Univ Med Sci. 2011;33(3):58-62. [Persian].

20. Abbasian L, Talebi F, Bazyar A, Shirbazo S, Sayehmiri K, Ahmadi N. Prevalence of Giardia lamblia in Iran: a systematic review and Meta analysis study. Research in Medicine. 2013;36(5):1116. [Persian].

21. Garedaghi Y. Parasitic protozoan among restaurant workers in Tabriz (East Azerbaijan province) Iran. Res J Biol Sci. 2011;6(6):272-4. doi:10.3923/rjbsci.2011.272.274

22. Davami MH, Rouhi R, Sadeghi AR. The prevalence of intestinal parasitic infections among 7-15 year old children in Jahrom, Iran, during 2006-7. Pars J Med Sci. 2008;6(6):49-55. [Persian].

(C) 2020 The Author(s); This is an open-access article distributed under the terms of the Creative Commons Attribution License (http:// creativecommons.org/licenses/by/4.0), which permits unrestricted use, distribution, and reproduction in any medium, provided the original work is properly cited. 